\title{
The Differences in Online Advertising Acceptance in China and Slovakia

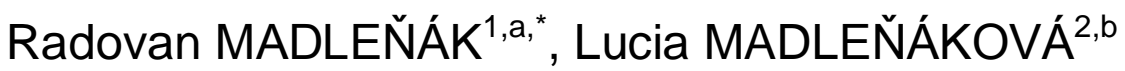

\author{
${ }^{1}$ Associate professor, Department of Communications, University of Žilina, Žilina, Slovakia \\ ${ }^{2}$ Associate professor, Department of Communications, University of Žilina, Žilina, Slovakia \\ aradovan.madlenak@fpedas.uniza.sk, 'lucia.madlenakova@fpedas.uniza.sk \\ ${ }^{*}$ Corresponding author
}

Keywords: Online marketing, Online advertising, Online advertising acceptance, China, Slovakia.

\begin{abstract}
Advertising, marketing and commercial activities on the Internet are the most recent trends of the last years. In most countries of the world, the Internet is operated on a fully commercial basis. More than a half of its users need it for commercial purposes. Marketing experts in businesses are the main users of information from the Internet. This article is focused at the acceptance of online advertising in China and compare the results of the Chinese and Slovak marketing researches.
\end{abstract}

\section{Introduction}

Advertisement spread out everywhere in our world. In every possible media, there are advertisements: TVs, Radios, Cinemas, Newspapers, and Streets. So, it is natural to find online advertisement at the web. This is a new way how to communicate, to buy and to search and it is a marvelous media for the advertisements, which are really important. For example, unsolicited advertisement emails represent nowadays more than $80 \%$ of the traffic on the network [1].

This article compares the customer's acceptance of the online advertising in different geographical locations in China and in Slovakia. As a lot of people seem to be annoyed by the online advertisements, the study will help us to know the exact situation of the online advertisements. With this study, we can compare intercultural acceptation of web advertisements and find some similarities of online advertisement in these two counties.

\section{Study aims}

This study has two main aims:

The improvement of the web use: With the knowledge of the Chinese customers' view at the online advertising, the use of the web will get better [2]. Either the online advertising are successful, either they fail. With the results, we can see that the feeling about the online advertising is bad and, however they think that the online advertising are succeeding which is a weird paradox we will explain.

The economic improvement of the Internet: the knowledge of the precise impact of the online advertising would be helpful to the firms, which use this kind of communication. Statistics like the click percentage, the acceptation of the different kind of online advertising will be precious indicators.

\section{Methodology}

To lead this study until the end, we used a precise methodology:

- Determination of the context: As the Internet is a new tool; its context can change rapidly. [3, 4] In fact there are apparitions of new phenomena, which need to be put together in order to explain the main issue of the survey. So we had to establish clearly the main issue:

Issue: How does the Chinese Internet customer react to the online advertisement?

- This issue will enlighten us about the real effect of the online advertising, its true success and, moreover with the comparison with the same survey realized is Slovakia [5, 6], differences between two different (geographical and cultural) countries. 
- Research: The form of research - quantitative questionnaires. To reach potential respondents we decided to use the questionnaire. Our target respondents were online users therefore the decision about medium was very simple. We used online questionnaire system installed at http:// fped.uniza.sk. The respondents of the questionnaire are the representative sample of population from China and from Slovakia (we set confidence interval estimate at 95\% and acceptable margin of error at $\pm 7 \%)$.

\section{Results}

The results of the questionnaire are divided to the four basic sections [7]:

- You and Internet,

- You and advertising,

- You and online advertising,

- Personal information.

The average Chinese person/respondent use Internet connection between at home or at work and is connected many times per day (Fig. 1). Almost the same results are at the Slovak part of research, where the typical respondent use the Internet mostly daily, but prevails the Internet connection from home.

Where do you use the Internet?

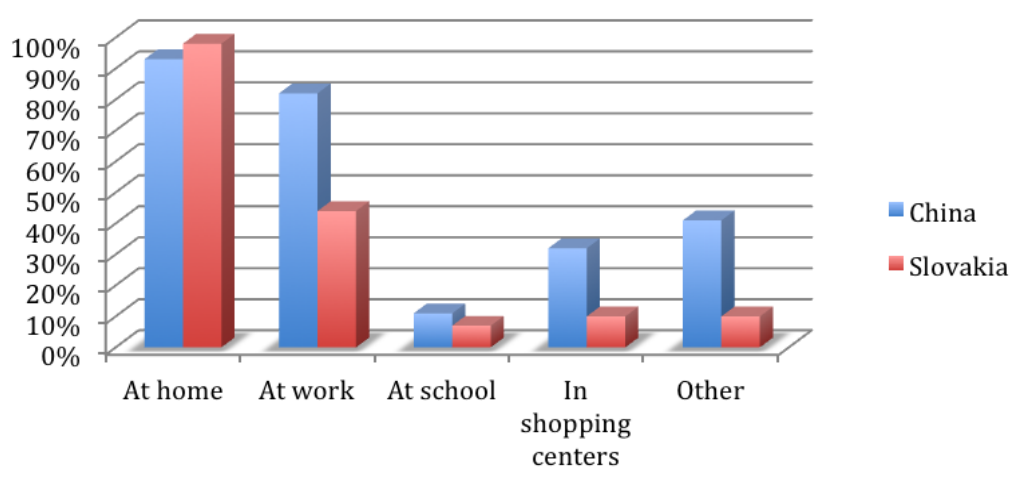

Figure 1 Place of Internet usage

The average person/respondent in China and in Slovakia has a different advertising form's preference. Slovak respondents prefer TV advertising to Internet advertising, but in the China respondents prefer Internet advertising. Very interesting finding is, that $23 \%$ of Chinese respondents preferring billboard advertising, in Slovakia it is only $6 \%$ of respondents.

What form of advertising do you prefer?

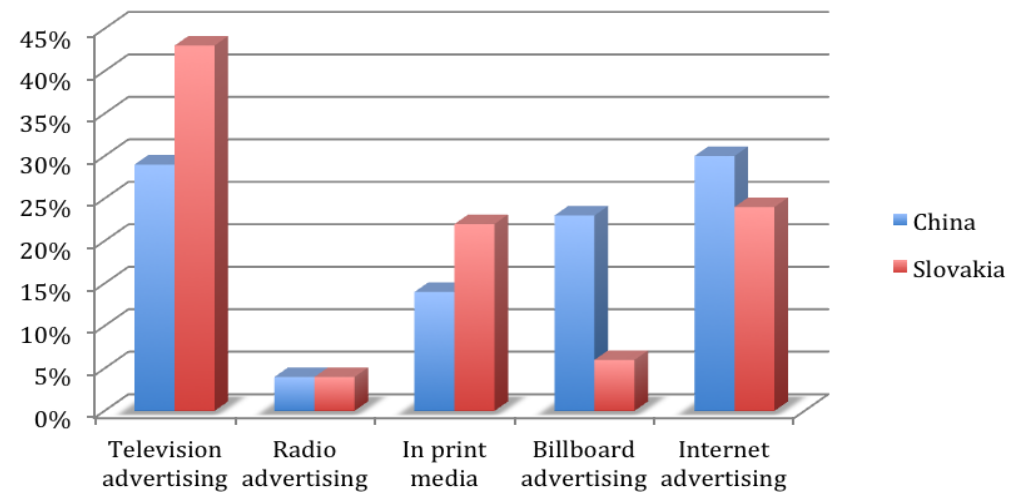

Figure 2 Preferable form of advertising

At the question: "How often are you in contact with advertising on the internet?" $47 \%$ of Chinese respondents answers that they have contact regularly, but in Slovakia 92\% of respondents have a 
regularly contact with Internet advertising. We can assume that the answer on the next question is based on previous experiences with Internet advertising.

What kind of relationship do you have with internet advertising?

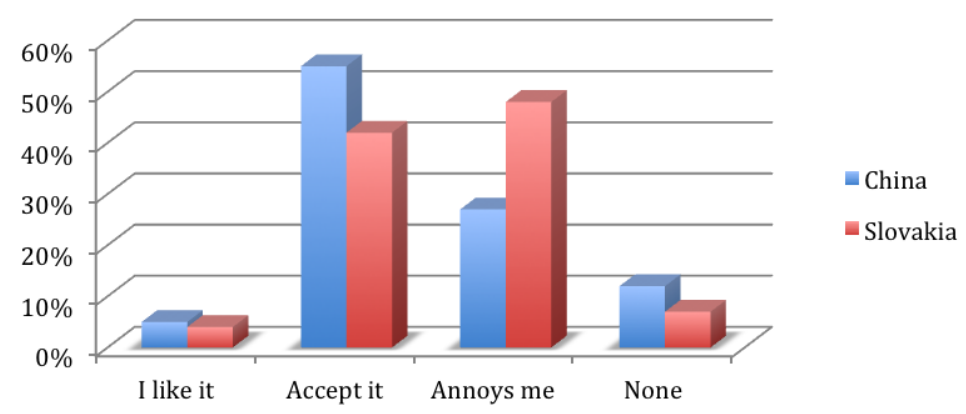

Figure 3 Acceptation of Internet advertising

$55 \%$ of Chinese respondents accepting Internet advertising (in Slovakia only $42 \%$ ), but internet advertising annoys $48 \%$ of Slovak respondents (against $27 \%$ respondents in China) (Fig. 3). For the respondents in both countries is the most important aspect of internet advertising content $(27 \%$ China and 30\% in Slovakia), but for Chinese respondents is very important if internet advertising has a good design - 18,5\% and is colorful - 10,5\% (in Slovakia its only $13 \%$ of respondents - design and $6 \%$ of respondents - colorful).

Negative experiences with internet advertising or some conservativism of slovak respondents we can find in their answers at the question: "Does the internet advertising affect your buying decision?". Answer "sometimes" checked only $48 \%$ of Slovak respondents, but $61 \%$ of Chinese respondents (Fig.4). The reasons of these answers we could find in more negative relationship with internet advertising in Slovakia then in China.

Does the internet advertising affect your buying decision?

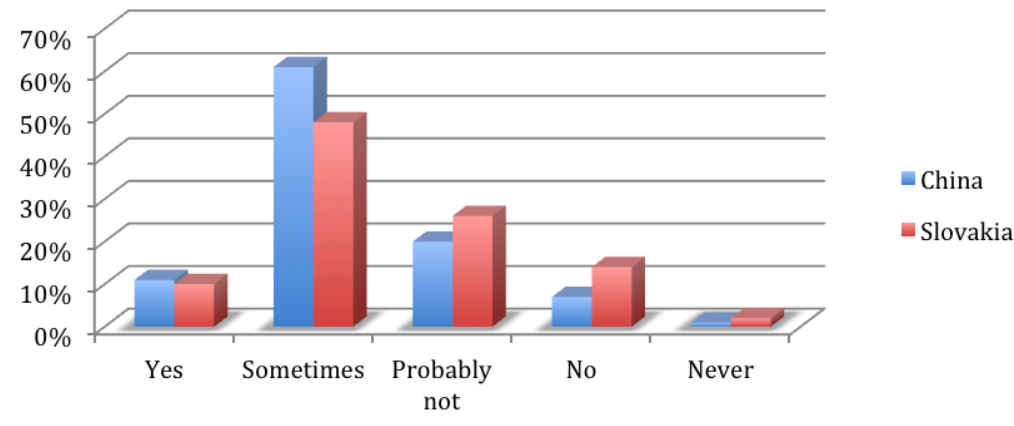

Figure 4 Impact of Internet advertising on buying decision

The similar results we could find in answers at the question: "How do you see the amount of online advertising market?" Relative optimistic views have 35\% of Chinese respondents. They declare, that at the market is reasonable amount of Internet advertising. Significantly negative opinion has $79 \%$ of Slovak respondents. They stated that the market with Internet advertising is oversaturated. Very interested finding that confirms previous questionnaire's results is statement that for $54 \%$ of Chinese respondents is Internet advertising source of information. On the other side, for $42 \%$ of Slovak respondents are Internet advertising unneeded.

Respondents in questionnaire could express the level of their acceptance of each type of advertising. In the Table 1 we can find different respondent's preferences in some forms of advertising. "Banners" are the most acceptable forms of internet advertising and "pop-up windows" 
dislikes people at the same level in China and in Slovakia, but Chinese respondents prefer "Display advertising" and Slovak respondents likes "Paid links" as form of internet advertising.

Table 1 Level of acceptation Internet advertising forms

\begin{tabular}{|l|c|c|c|c|c|c|c|c|c|c|}
\cline { 2 - 12 } \multicolumn{1}{c|}{} & \multicolumn{2}{c|}{ The Best } & \multicolumn{2}{c|}{ Good } & \multicolumn{2}{c|}{ Normal } & \multicolumn{2}{c|}{ Bad } & \multicolumn{2}{c|}{ The Worst } \\
\hline Advertising form & China & Slovakia & China & Slovakia & China & Slovakia & China & Slovakia & China & Slovakia \\
\hline Banners & $31,5 \%$ & $25,1 \%$ & $32,9 \%$ & $17,9 \%$ & $18,2 \%$ & $28,5 \%$ & $6,3 \%$ & $13,5 \%$ & $11,2 \%$ & $17,9 \%$ \\
\hline Pop-up windows & $7,8 \%$ & $1,9 \%$ & $12,7 \%$ & $2,9 \%$ & $9,2 \%$ & $13,5 \%$ & $4,9 \%$ & $20,3 \%$ & $65,5 \%$ & $62,3 \%$ \\
\hline Intertitial advertising & $9,9 \%$ & $1,9 \%$ & $15,5 \%$ & $11,2 \%$ & $12 \%$ & $22,8 \%$ & $18,3 \%$ & $18,9 \%$ & $44,4 \%$ & $46,6 \%$ \\
\hline Email advertising & $11,4 \%$ & $7,4 \%$ & $18,4 \%$ & $12,4 \%$ & $25,5 \%$ & $27,7 \%$ & $19,2 \%$ & $17,8 \%$ & $25,5 \%$ & $37,6 \%$ \\
\hline Display Advertising & $15,6 \%$ & $2 \%$ & $38,3 \%$ & $11 \%$ & $27 \%$ & $34 \%$ & $9,9 \%$ & $24 \%$ & $9,2 \%$ & $31 \%$ \\
\hline Paid Links & $11,4 \%$ & $17,7 \%$ & $20 \%$ & $14,1 \%$ & $26,4 \%$ & $27,8 \%$ & $26,4 \%$ & $18,7 \%$ & $15,1 \%$ & $23,7 \%$ \\
\hline Other & $9,9 \%$ & $7,4 \%$ & $11,5 \%$ & $8,3 \%$ & $47,3 \%$ & $47,9 \%$ & $20,6 \%$ & $17,4 \%$ & $10,7 \%$ & $19 \%$ \\
\hline
\end{tabular}

The last question was about most important features of Internet advertising. In our research we discover very interesting findings. For Slovak respondents are very important all mentioned features of Internet advertising (truthful, credibility, understanding, non-vulgarity, originality, and funny). But Chinese respondents are not so strict in these Internet advertising features. The level of importance is lower and its very interesting that they are tolerant to some level of vulgarism in Internet advertising.

Table 2 Importance of Internet advertising features

\begin{tabular}{|l|c|c|c|c|c|c|c|c|c|c|}
\cline { 2 - 12 } \multicolumn{1}{c|}{} & \multicolumn{2}{c|}{ Very important } & \multicolumn{2}{c|}{ Important } & \multicolumn{2}{c|}{ Neutral } & \multicolumn{2}{c|}{ Less important } & \multicolumn{2}{c|}{ Unimportant } \\
\hline Advertising features & China & Slovakia & China & Slovakia & China & Slovakia & China & Slovakia & China & Slovakia \\
\hline Truthful & $64,8 \%$ & $87,8 \%$ & $13,1 \%$ & $10,7 \%$ & $13,1 \%$ & $3,1 \%$ & $0,7 \%$ & $0,5 \%$ & $8,3 \%$ & $2,6 \%$ \\
\hline Understanding & $49,7 \%$ & $71,1 \%$ & $28,4 \%$ & $20,1 \%$ & $12,8 \%$ & $5,4 \%$ & $2,1 \%$ & $1,5 \%$ & $7,1 \%$ & $2,5 \%$ \\
\hline Credible & $43,6 \%$ & $72 \%$ & $26,4 \%$ & $22 \%$ & $19,3 \%$ & $3,5 \%$ & $2,9 \%$ & $1 \%$ & $7,9 \%$ & $2,5 \%$ \\
\hline Without vulgarisms & $23,1 \%$ & $69,5 \%$ & $26,6 \%$ & $15,2 \%$ & $35 \%$ & $9,1 \%$ & $6,3 \%$ & $2,5 \%$ & $9,1 \%$ & $6,6 \%$ \\
\hline Original & $46,4 \%$ & $64,9 \%$ & $24,3 \%$ & $15,8 \%$ & $16,4 \%$ & $14,4 \%$ & $4,3 \%$ & $3 \%$ & $8,6 \%$ & $3 \%$ \\
\hline Funny & $38,2 \%$ & $46,9 \%$ & $31,3 \%$ & $21,7 \%$ & $18,8 \%$ & $22,2 \%$ & $4,9 \%$ & $5,2 \%$ & $6,9 \%$ & $7,2 \%$ \\
\hline
\end{tabular}

The average person/respondent in China and in Slovakia is a woman (more than $60 \%$ of respondents), she is between 20 and 39 years old (about $80 \%$ of respondents). She lives in city, she has university degree (bachelor or master level) and she is employed.

\section{Conclusion}

According realized two researches we can find some differences in relationship between Internet users and advertising in China and Slovakia. The most interesting cultural differences are:

- The most preferable type of advertising in Slovakia is TV advertising and relative high preferences of billboard advertising in China.

- Higher level of Internet advertising acceptation in China then in Slovakia.

- Some negative experiences of Slovak respondents with Internet advertising result to low influence of internet advertising on buying decision in Slovakia.

- Slovak respondents think Internet is oversaturated with advertising.

- For Chinese respondents is important nice design and colorful of advertising,

- Chinese respondents accepting the Internet advertising with some level of vulgarism.

On the basis of these findings is possible to identify some critical factors that are important for understanding situation, conditions and preferences of advertising market in this different countries.

\section{Summary}

This article deals with the problem of comparison of Internet advertising in Slovakia and China. Mention the difference between the preferences of Slovak and Chinese Internet users. On the basis of 
the current state of the Internet and Internet advertising in Slovakia and China and realized marketing researches in China and in Slovakia, we tried to identify the common and different aspects of Internet advertising. This research could be some kind of instruction how to provide successful business activities in these different cultural conditions.

\section{Acknowledgement}

This research was financially supported by project KEGA 053ZU-4/2013 - Quality improvement and key subjects' interconnection of study program "Ecommerce and management".

\section{References}

[1] Campbell, C., Pitt, L.F., Parent, M., Berthon, P.R.: Understanding Consumer Conversations Around Ads In A Web 2.0 World, In: Journal of Advertising, Volume: 40, Issue: 1 (2011), 87-102, ISSN 0091-3367.

[2] Zhang, J., Mao, E.: Understanding the acceptance of mobile SMS advertising among young Chinese consumers, In: Psychology \& Marketing, Volume: 26, Issue: 8 (2008), 787-805, ISSN 0742-6046.

[3] Majerova, J., Krizanova, A., Zvarikova, K.: Social media marketing and possibilities of quantifying its effectiveness in the process of brand value building and managing, In: Financial Management of Firms and Financial Institutions: 9th International Scientific Conference Proceedings, Pts I-III, 2013, 476-485, ISBN 978-80-248-3172-5.

[4] Madlenak, R., Madlenakova, L., Strbova, J., Stefunko, J.: Logo creation algorithm, In: Komunikacie, Volume: 16, Issue: 3 (2014), 120-124, ISSN 1335-4205.

[5] Madlenak, R., Madleňáková, L.: Digital Advertising System in Urban Transport System of Zilina Town, In: Transport and Telecommunication, Volume: 15, Issue: 3 (2014), 215-226, ISSN 1407-6160.

[6] Madlenak, R., Svadlenka, L.: Acceptance of Internet Advertising by Users in The Czech Republic, In: E \& M Ekonomie a Management, Volume: 12 Issue: 1 (2009), 98-107, ISSN 1212-3609.

[7] Castaneda, J.A., Rodriguez, M.A., Luquie, T.: Attitudes' hierarchy of effects in online user behaviour, In: Online Information Review, Volume: 33, Issue: 1 (2009), 7-21, ISSN 1468-4527. 